\title{
Relationship of musculoskeletal pain with physical and functional variables and with postural changes in school children from 6 to 12 years of age
}

\author{
Daniela S. L. Pereira ${ }^{1}$, Shamyr S. Castro ${ }^{2}$, Dernival Bertoncello ${ }^{2,3}$, \\ Renata Damião ${ }^{3,4}$, Isabel A. P. Walsh ${ }^{2}$
}

\begin{abstract}
Background: Painful disorders can affect children and adolescents, causing distress and significant demand for health services. Objective: To identify the prevalence of musculoskeletal pain and its relation to age, sex, body mass index (BMI), how to carry school supplies, postures used in ADLs, outside school physical exercises and postural changes in students. Method: Cross-sectional exploratory study with a convenience sample consisted of 262 schoolchildren aged 6 to 12 years ( 137 female). Data collection was conducted by questionnaire containing personal data, presence and location of pain, means of transportation and illustrative figures for choosing the way of carrying school supplies and postures ADL's. Postural evaluation was performed by observational analysis and body mass index calculated from information on height, weight, age and sex. Descriptive analysis was carried out with numbers and percentages. For inferential statistics, comparison of average age according to the presence of pain was performed by Kruskal-Wallis with Dunn's post-test. Categorical variables were compared with chi-square test. Results: The presence of musculoskeletal pain was reported by $51.1 \%$ of the students and $38.93 \%$ had pain in only one region. The most affected regions were legs, spine, arms and shoulders. The pain increased with age and with physical activity. Conclusions: In the our sample, $51.1 \%$ of students reported pain and $38.93 \%$ reported pain in only one region. There was no association between the presence of pain and sex, BMI, how to carry school supplies, postures used in ADLs and postural changes. The increasing age and physical exercise influenced significantly the presence of pain.
\end{abstract}

Keywords: physical therapy; child; pain; movement; posture.

\section{HOW TO CITE THIS ARTICLE}

Pereira DSL, Castro SS, Bertoncello D, Damião R, Walsh IAP. Relationship of musculoskeletal pain with physical and functional variables and with postural changes in school children from 6 to 12 years of age. Braz J Phys Ther. 2013 July-Aug; 17(4):392-400. http://dx.doi.org/10.1590/S1413-35552012005000106

\section{Introduction}

Many painful conditions, of acute or chronic nature, can affect children and adolescents, generating suffering and significant demand for health services ${ }^{1}$.

Because the genesis of pain is complex and complaints are usually vague and subjective, its approach can become an arduous task. Often a reductionist and simplistic stance is observed when faced with this problem, where the symptoms are not adequately valued, or at the other extreme, excessive laboratory investigations are requested, losing sight of the child as a whole ${ }^{1}$.

The experience of pain is subjective and multifactorial, influenced by its perception and manifestation, hindering an objective evaluation in clinical practice. Several factors are related to musculoskeletal pain, including age, gender, height, weight, body mass index (BMI), physical activity levels, postural changes and school-related factors such as the furniture ${ }^{2-4}$. However, childhood and adolescence are the most important periods for the formation of the musculoskeletal system, and physical problems that occur in this phase can be a determining factor for irreversible dysfunctions during adulthood ${ }^{5}$ because bones and muscles are under development during this period.

A study by Fernandes et al. ${ }^{6}$ revealed a satisfactory adherence to an educational intervention model proposed among school children and performed by physical therapists, indicating the significant role of this professional in school health.

Considering that schools are ideal places to conduct actions that favor the adequate physical and motor 
development of children, a better understanding of musculoskeletal pains and related factors allows for the physical therapists to apply resources that are available to them in school interventions, favoring the information and prevention in these places, as well as early diagnosis and referral to specific treatment.

In this perspective, this study aimed to identify the prevalence of musculoskeletal pain (located on limbs and spinal column) and its relation to age, gender, BMI, how school supplies are carried, postures used in activities of daily living (ADLs), physical activity outside of the school environment and postural changes in school children from six to 12 years of age in a public school in Uberaba, state of Minas Gerais (MG), Brazil.

\section{- Method}

\section{Type of study, sample and legal aspects of the study}

This study is characterized by being a crosssectional exploratory field study.

The project was approved under number 1731 by the Research Ethics Committee of the Universidade Federal do Triângulo Mineiro (UFTM), Uberaba, MG, Brazil. Parents or guardians were informed about the objectives and methodology of the study, and freely signed an informed consent (Resolution number 196, October $10^{\text {th }}, 1996$ of the National Health Council, which regulates research involving human beings).

The sample was selected by convenience, and consisted of 262 students of both sexes, aged six to 12 years, from a state school in Uberaba, MG, Brazil, located in the area covered by one basic health unit, in which the Educational Program for Health Work - PET Health (Programa de Educação pelo Trabalho para a Saúde - PET Saúde) from the UFTM operates.

Children whose guardians did not sign the consent form, or that during the pain evaluation reported the presence of non-musculoskeletal pain (head, stomach and eyes) were excluded.

Data collection was conducted from March through November of 2010.

\section{Procedure for data collection}

Evaluations were performed on school grounds with permission from the board of directors of the school. Study participants had to have the term of consent duly signed by their parents or guardians. The questionnaire was initially applied in the classroom, monitored by the scholars participating in the extension project: "Avaliação fisioterapêutica e nutricional em escolares [Physical therapy and nutritional evaluations in school children]" and of the PET Health of the UFTM. Students were then evaluated at the school yard, where they were evaluated one by one, in a private room, regarding their body mass and postural changes.

\section{Instruments for data collection}

A questionnaire was developed specially for this study, composed of questions covering personal data, presence and location of pain, physical activities outside of school, and illustrations that allowed the students to choose how they carried their school supplies, and postures that they adopted in ADLs.

Existence and location of pain were reported according to its presence or absence in each of the seven options: arms, spine, shoulders, hands, legs, feet and others (in the presence of the latter option, the site was described).

Physical exercise outside of school was selfreported, using the option 'yes' or 'no'.

The way in which school supplies were carried was assessed by using ten illustrations, so the students could pick the illustration that most resembled how they carried their school supplies. The way the students carried the school supplies was considered to be adequate when the backpack was worn with both straps on the back and at waist height, and as inadequate when carried by only one strap, with the straps too low or too high (considering the waist line) or when the school supplies were hand carried with no backpack.

The postures adopted in ADLs encompassed studying at home or school (six choices of illustrations), watching TV (five choices of illustrations), computer use (six choices of illustrations) and video game use (five choices of illustrations). The school children should choose the illustration that most closely resembled their posture for each of those options. To analyze this variable, four categories were established: the majority of the activities were not performed on a daily basis; adequate postures were used to carry out most activities (sitting on the ischia, with a lumbar support and support of the lower limbs); inadequate postures were used to carry out most activities (remain sitting without a lumbar support or support of the lower limbs, or laying down) and adopted adequate and inadequate postures in equal proportions.

Body mass was determined using a portable platform-type digital scale, with capacity 
to up to $150 \mathrm{Kg}$ and sensitivity of $50 \mathrm{~g}$, in which the school child was weighed barefoot and wearing light clothing. Height was measured while the children were standing, barefoot with neck, buttocks and heels aligned, using a portable stadiometer. From information on height, body mass, age and gender, the body mass index/age (BMI/A) was calculated. Nutritional status was evaluated by calculating the $\mathrm{z}$ score for the BMI/A index, according to the standards proposed by the World Health Organization ${ }^{7}$. Because no child was classified as being severely underweight, an underweight/normal-weight category was created. No child was classified as being morbidly obese either, so the category overweight/obesity was created. Thus, two categories were defined for analysis.

Postural assessment was performed by observational analysis by fourth- and fifth-year physical therapy students of the referred institutions, which were properly trained. This assessment was validated through a pilot test with ten school children that were then excluded from the sample. The students were told to stay for a few minutes standing, relaxed, with the upper limbs along their trunk and bare feet, keeping their body weight evenly distributed.

Each child was evaluated individually and only once in the coronal (anterior and posterior) and sagittal (lateral) planes. The following parameters were evaluated: alignment of shoulder and pelvic girdles, alignment of anterior-superior iliac spines, ankle and knee deviations, occipital-thorax-buttocks alignment, head protrusion and lateral deviation of the vertebrate ${ }^{8,9}$. Fifteen possibilities of changes were established and grouped into three categories: changes in the upper limbs (shoulder retraction, shoulder protrusion, shoulder height differences); changes in the lower limbs (knee hyperextension, varus knee, valgus knee and flat feet); changes in the trunk (pelvic anteversion, pelvic retroversion, scoliosis, hyperlordosis, hyperkyphosis, protruding abdomen, head projected forward, head tilt), and the amount of change in each category was recorded.

\section{Data analysis}

The questionnaire data were stored in a spreadsheet using Microsoft Excel 2007.

The presence of pain was considered the dependent variable, and the independent variables were as follows: age, gender, physical exercise outside of school, how school supplies were carried, postures during ADLs, postural changes in upper limbs, lower limbs and trunk.
For the descriptive analysis of the data, raw values and percentages were used. For inferential statistics, comparison of the median age according to the presence of pain was performed by Kruskal-Wallis test with Dunn's post-test. Categorical variables were compared with chi-square test. The significance level adopted was 5\%.

\section{Results}

The sample consisted of 262 school children between the ages of six and 12 years (Mean $=7.91$; Standard Deviation=1.38), 125 males and 137 females.

The presence of musculoskeletal pain was reported for $134(51.1 \%)$ of the school children. One hundred and two school children (38.93\%) reported pain in only one region, followed by $24(9.16 \%)$ with pain in two regions, four $(1.53 \%)$ in three regions, three $(1.15 \%)$ in four regions and one $(0.38 \%)$ in five regions. The results indicated that the most affected areas were legs and spine (Figure 1).

The results of the associations between the presence of pain and other variables are shown in Tables 1, 2 and 3.

There was a statistically significant association between age and presence of pain $(p=0.0001)$, indicating that pain manifests itself more frequently in older school children because the mean age for school children without pain was $7.53 \pm 1.34$ and for children with pain was $8.26 \pm 1.32$. No significant association was found between presence of pain and gender, BMI, how school supplies are carried and postures adopted during ADLs. There was a significant association between presence of pain and physical exercise $(p=0.05)$. No significant associations were found between the presence of

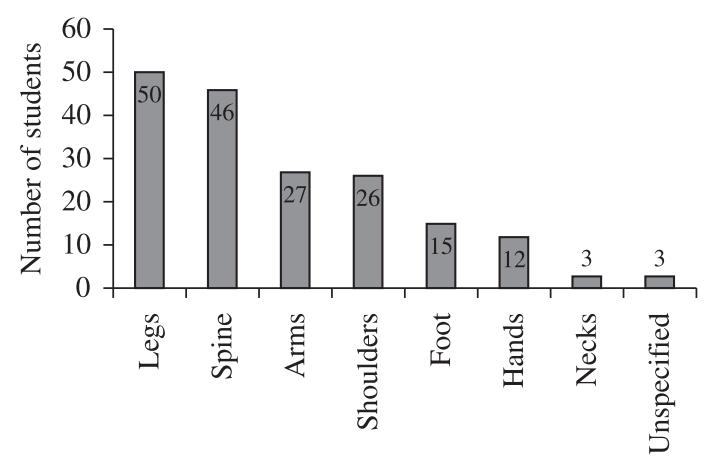

Figure 1. Number and location of pain by body region. 
Table 1. Association between presence of pain and variables: Age, Sex, BMI and oriented physical exercise outside school.

\begin{tabular}{|c|c|c|c|c|}
\hline \multirow{2}{*}{ Variables } & \multicolumn{4}{|c|}{ Pain presence } \\
\hline & No & Yes & Total & $\mathbf{p}$ \\
\hline \multirow[t]{3}{*}{ Age } & $\mathrm{M}(\mathrm{DP})$ & $\mathrm{M}(\mathrm{DP})$ & $\mathrm{M}(\mathrm{DP})$ & $0,0001 * *$ \\
\hline & $7.53(1.34)$ & $8.26(1.32)$ & $7.90(1.38)$ & \\
\hline & $\mathbf{N}(\%)$ & $\mathbf{N}(\%)$ & $\mathbf{N}(\%)$ & \\
\hline Sex & & & & 0.79 \\
\hline Male & $60(48.00)$ & $65(62.00)$ & $125(100)$ & \\
\hline Female & $68(49.63)$ & $69(50.36)$ & $137(100)$ & \\
\hline BMI* & & & & 0.88 \\
\hline Underweight/normal weight & $92(48.17)$ & $99(51.83)$ & 191(100) & \\
\hline Overweight/ Obese & $34(49.28)$ & $35(50.72)$ & $69(100)$ & \\
\hline Pysical exercises & & & & 0.05 \\
\hline Yes & $46(41.82)$ & $64(58.19)$ & $110(100)$ & \\
\hline No & $82(53.95)$ & $70(46.05)$ & $152(100)$ & \\
\hline
\end{tabular}

* 2 looses; **Kruskal-Wallis test.

Table 2. Associations between presence ofpainand variables: How school supplies are carried and postures DLA's.

\begin{tabular}{|c|c|c|c|c|}
\hline \multirow{2}{*}{ Variables } & \multicolumn{3}{|c|}{ Pain presence } & \multirow[b]{2}{*}{$\mathbf{p}$} \\
\hline & No N $(\%)$ & Yes N (\%) & Total N (\%) & \\
\hline Carrying material & & & & 0.88 \\
\hline Adequate & $110(48.67)$ & $116(51.33)$ & $226(100)$ & \\
\hline Inadequate & $18(50.00)$ & $18(50.00)$ & $36(100)$ & \\
\hline Postures in DLA & & & & 0.28 \\
\hline Does not perform & $16(61.54)$ & $10(38.46)$ & $26(100)$ & \\
\hline Adequate & $38(46.34)$ & $44(53.66)$ & $82(100)$ & \\
\hline Adequate/inadequate & $34(54.84)$ & $28(45.16)$ & $62(100)$ & \\
\hline Inadequate & $40(43.48)$ & $52(56.52)$ & $92(100)$ & \\
\hline
\end{tabular}

DLA: daily life activities.

pain and postural changes in the upper limbs, lower limbs and trunk.

\section{Discussion}

This study found that $134(51.1 \%)$ of evaluated school children reported musculoskeletal pain, and the most affected areas were legs and spine. There was a significant association between age and presence of pain. However, pain was not associated with gender, BMI, how the school supplies were carried, and postures in ADLs.

Mikkersson et al. ${ }^{10}$ evaluated for a year the prevalence of these painful symptoms and disabilities in Finish school children in the third and fifth grades, and found that half of the pre-adolescents with pain complaints at least once a week felt pain until the end of the study period. In Brazil, Puccini and Bresolin ${ }^{1}$ observed the presence of musculoskeletal pain in children and adolescents, attributing as possible causes: growing pains, fibromyalgia, joint hypermobility and structural and postural changes.

However, Barbosa et al. ${ }^{11}$, while assessing limb pain in a pediatric rheumatology service, observed that limb pain was not associated with joint hypermobility or fibromyalgia in half of the children evaluated. Thus, it is difficult to be sure of this association because external factors, including physical effort related to the misuse of backpacks, sports activities, physical activity in excess, staying 
Table 3. Associations between presence of pain and postural changes in Upper Limbs, Lower limbs and Trunk.

\begin{tabular}{|c|c|c|c|c|}
\hline \multirow{3}{*}{ Variables } & \multicolumn{4}{|c|}{ Pain presence } \\
\hline & No & Yes & Total & $\mathbf{p}$ \\
\hline & $\mathrm{N}(\%)$ & $\mathrm{N}(\%)$ & $\mathrm{N}(\%)$ & \\
\hline UL alteration & & & & 0.67 \\
\hline 0 & $17(48.57)$ & $18(51.43)$ & $35(100)$ & \\
\hline 1 & $53(44.92)$ & $65(55.08)$ & $118(100)$ & \\
\hline 2 & $57(53.27)$ & $50(46.73)$ & $107(100)$ & \\
\hline 3 & $1(50.00)$ & $1(50.00)$ & $2(100)$ & \\
\hline LL alteration & & & & 0.67 \\
\hline 0 & 19(44.19) & $24(55.81)$ & $43(100)$ & \\
\hline 1 & $38(45.24)$ & $46(54.76)$ & $84(100)$ & \\
\hline 2 & $46(52.87)$ & 41(47.13) & $87(100)$ & \\
\hline 3 & $25(52.08)$ & $23(47.92)$ & $48(100)$ & \\
\hline Trunk alterations & & & & 0.71 \\
\hline 0 & $19(47.50)$ & $21(52.50)$ & $40(100)$ & \\
\hline 1 & $49(46.67)$ & $56(53.33)$ & $105(100)$ & \\
\hline 2 & $33(54.10)$ & $28(45.90)$ & $61(100)$ & \\
\hline 3 & $25(51.02)$ & $24(48.98)$ & $49(100)$ & \\
\hline 4 & $2(28.57)$ & $5(71.43)$ & $7(100)$ & \\
\hline
\end{tabular}

UL alteration: Upper limb alteration; LL alterations: Lower limb alterations.

in the seated position for extended periods of time using video games or computers, can be identified as risk factors and may be related to the presence of limb pain.

Emotional issues, particularly situations that cause anxiety, frustration and sadness, and psychological stress are also described in the literature as factors that triggers or worsens the pain. However, these variables were not the focus of the present study. Thus, future studies are recommended to elucidate the association of emotional and physical variables in school children.

With respect to the location of the musculoskeletal pain, the regions most affected were legs and spine. Studies have reported lumbar pain as the main complaint ${ }^{12,13}$, but pain in the neck, shoulders, vertebra and lower limbs have also been reported ${ }^{14-17}$. However, the results of this study do not explain the causes of higher prevalence of pain in these regions because what were analyzed were the factors associated with presence of pain in the musculoskeletal system globally. Therefore, future studies can perform analysis on the factors associated with pain per affected area to better explain the findings herein.
In this study, age was a significant factor for the presence of pain, with a higher prevalence of pain in older school children. Watson et al. ${ }^{18}$, Taimela et al. ${ }^{19}$ and Rebolho et al. ${ }^{20}$ showed an increase in back pain with age in school children. According to Trevelyan and Legg ${ }^{4}$ and Rebolho et al. ${ }^{20}$, age has a positive relation with the occurrence of musculoskeletal pain. Molina et al. ${ }^{14}$ stated that the majority of the cases involved children in late childhood and early adolescence.

In this sense, Smith and Legatt ${ }^{21}$ discussed data from several studies that have shown that this increase in pain prevalence with age may be related to changes in the nature of the activities of these children as they evolve to higher levels of education. While one expects that students in the beginning of their education have a large component of play in their daily activities, older students are expected to have a proportionally greater exposure to computers and study hours, and thus an overload of static postures. It is also expected that older children have a greater amount of school supplies to carry, which would increase the weight of their backpacks.

With respect to gender, although in this study boys showed a higher prevalence of pain (62\%) 
than the girls $(50.36 \%)$, this association was not significant. There is controversy in the literature on the relation between pain and gender. A study by Rebolho et al. ${ }^{20}$ showed a higher prevalence of pain reported by males, differing from the results of Taimela et al. ${ }^{19}$, El-Metwally et al. ${ }^{17}$ and Garetth and Gary $^{22}$, that observed a higher prevalence of low back pain and other musculoskeletal pain in females. Imamura et al. ${ }^{23}$ also found no gender difference. The fact that there was no influence of gender in the presence of pain in the present study can be explained by recent reviews on the subject that state that the differences only become important starting at puberty ${ }^{24}$, associated with the increasing hormonal influence that characterizes that period ${ }^{25}$.

Siambanes et al. ${ }^{26}$ report that females refer more to pain than males at the beginning of maturity because girls begin puberty two years earlier than boys, while Trevelyan and $\mathrm{Legg}^{4}$ report that the traditional notion of masculinity causes boys to be ashamed to report pain.

This study did not find an association between musculoskeletal pains and BMI in the evaluated school children. As the sample was classified heterogeneously with respect to this variable, with the majority of school children belonging to the underweight/normal-weight category, this may have affected the statistical comparison. However, this lack of association has also been reported in another study, where there was no evidence of a relation between obesity and the musculoskeletal system in children, but it is assumed that obesity affects the locomotor apparatus, structurally and functionally, with joint overloading and malalignment ${ }^{27}$.

Although several studies indicate the importance of the way to carry the backpack and of the postures adopted for the performance of ADLs in musculoskeletal pain, in the present study no significant associations were found between these variables. The results herein agree with those of Siambanes et al. ${ }^{26}$, who did not find a relation between how the backpack was carried and pain. Those results can be related to the weight of the backpack and not only the way it is carried Studies by Grimmer and Willians ${ }^{28}$, Iyer ${ }^{16}$ and Siambanes et al. ${ }^{26}$ reported that the weight of the backpack is related to back pain, and Negrini and Carabalona ${ }^{29}$, to shoulder pain, and that can influence the onset of pain and other events such as postural deviations ${ }^{30}$, because the presence of asymmetry in the distribution of plantar force and oscillations of the center of pressure were identified as resulting from the habit of carrying their school material with inappropriate loads and positioning ${ }^{31}$. Thus, the absence of data relating to weight carried in each backpack can be regarded as a weakness in this study because this is an important variable that should be evaluated in further studies.

As for the postures adopted in ADLs, Puccini and Bresolin ${ }^{1}$ report that the excessive use of computers and videogames have been decisive for localized or diffuse musculoskeletal pain. Santos et al..$^{32}$ found that school children with a mean age of 12.8 years showed specific musculoskeletal pains resulting from sitting incorrectly during classes.

The present study also did not find a significant relationship between musculoskeletal pain and postural changes. Some studies have reported such associations. Korovessis et al. ${ }^{33}$ related cervical hyperlordosis, head anteriorization and shoulder elevation with back pain. Contri et al. ${ }^{34}$ stated that pain is one of the major complications of scoliosis in school children from second to fifth grades. Rego and Scartoni ${ }^{35}$ have shown that posture changes may give rise to pain in school children from fifth to sixth grades. The results herein could have been influenced by the method used (observational analysis), which may not have been sensitive enough to detect such relations because posture is a complex phenomenon and difficult to quantify. Future studies should consider the use of quantitative measures of posture, such as photogrammetry which was shown to be a suitable and reliable quantitative method in Santos et al. ${ }^{36}$ study, and protocols based on the marking of anatomical points and calculations of angles and postural deviations.

The non-significant results found in the present study suggest that psychosocial factors may also influence the occurrence of pain in school children, in addition to mechanical factors related to postures adopted in ADLs and postural changes. Watson et al. ${ }^{18}$ investigated an association between mechanical and psychosocial factors in low back pain among school children. The evaluation of psychosocial factors included a questionnaire about behaviors, emotions, and relationships of the adolescents, suggesting that psychosocial factors were more important than the mechanical factors in the genesis of this pathology. Thus, further studies are required to investigate these factors in determining pain in school children.

It can also be inferred that, in this age group, symptoms resulting from mechanical factors related to postures adopted in ADLs and postural changes have not yet been manifested, such as pain, and that they can manifest themselves in a greater number of subjects and at a higher intensity in adult life ${ }^{37}$. Thus, poor body positioning during ADLs may have even greater consequences in the long run on the joint structures still under development in school children. 
This fact becomes more worrisome when children with posture changes show no pain, which denotes adaptation to poor body posture adopted in everyday life and reinforces the need to encourage postural assessment and early detection of these changes.

There was a significant association between physical exercise and musculoskeletal pain, with students who exercise showing more pain than those who do not. This fact can be explained by a number of factors, such as the type of sport, level of demand, intensity of training and degree of acute trauma generated by the sport, especially in children and adolescents ${ }^{38,39}$. This finding could also be explained by the increasing participation of children and adolescents in sports, especially competitive, early and with insufficient physical preparation, which may cause overload and subsequent inflammation, pain and functional disability, establishing a relation between musculoskeletal pain and physical activity by the overuse theory, leading to microtrauma and subsequent pain, edema and functional disabilities, and the possibility of stress fractures ${ }^{1}$. However, the data presented should be interpreted with caution because the collection of data about physical exercises was performed by self-report, and no instruments were used to evaluate the modality, frequency, classification (light, moderate, heavy, competitive modalities) of the exercises. Therefore, studies that use validated instruments to evaluate physical activity should be encouraged.

Studies that work with random samples and selection of various schools can significantly contribute to improving knowledge in this field. Furthermore, lack of a more detailed analysis of pain using a greater number of instruments could be identified as another limiting factor. Therefore, future studies may include variables such as the time interval between the occurrence of pain, frequency of pain and other aspects that influence the evaluation the children make of their pain. However, this is not an easy task because pain perception can be reported in various ways as a function of several factors, such as environment, cultural level, social-economical level and life period. In addition, it is pertinent to emphasize the importance of physical exercise in a guided manner, with structured programs and accompanied by qualified professionals, so that the goals can be achieved, and consequently have a positive impact in the growth and school development, enabling socialization, promotion of motor skill, self-knowledge of the body, improvement of self-esteem and aid in the prevention of obesity and other chronic-degenerative diseases.

\section{Conclusion}

The present study found a prevalence of musculoskeletal pain of $51.1 \%$. No significant associations were found between the presence of pain, and gender, BMI, how school supplies were carried, postures adopted in ADLs and postural changes. Increasing age and physical activity significantly influenced the presence of pain.

Considering that schools are ideal places to conduct activities that favor proper physical and motor development in children, a better understanding of the relation between musculoskeletal pain and related factors allow physical therapists to apply the resources that are available for information, prevention and early diagnosis in school setting, as well as refer to specific therapies.

\section{References}

1. Puccini RF, Bresolin AM. Dores recorrentes na infânciaeadolescência. J Pediatr. 2003;79(Supl.1):S65-S73. http://dx.doi.org/10.1590/S0021-75572003000700008

2. Balagué F, Trussier B, Salmien J. Non-Specific Low Pain in Children and Adolescentes: Risk Factors. Eur Spine J. 1999;8(6):429-38. http://dx.doi.org/10.1007/ s005860050201

3. Burton AK, Balagué F, Cardon G, Eriksen HR, Henrotin Y, Lahad A, et al. Chapter 2. European guidelines for prevention in low back pain: November 2004. Eur Spine J. 2006;15(Suppl 2):S136-S168. http://dx.doi.org/10.1007/ s00586-006-1070-3

4. Trevelyan F, Legg S. Back Pain in School Children - Where to from here? Appl Ergon. 2006;37:45-54. http://dx.doi. org/10.1016/j.apergo.2004.02.008

5. Kavalco TF. A manifestação de alterações posturais em crianças de primeira a quarta séries do ensino fundamental e sua relação coma ergonomia escolar. Rev Bras Fisioter. 2000;4(2).

6. Fernandes SMS, Casarotto RA, João SMA. Efeitos de sessões educativas no uso das mochilas escolares em estudantes do ensino fundamental I. Rev Bras Fisioter. 2008;12(6):447-53. http://dx.doi.org/10.1590/ S1413-35552008005000002

7. World Health Organization - WHO. Child Growth Standars. Length/height-for-age, weight-for-age, weightfor-length, weight-for-height and body mass indexfor-age: methods and development. Geneva: WHO Departament of Nutrition for Health Development; 2006.

8. Kendal FP, McCreay EK, Provance PG. Postura: alinhamento e equilíbrio muscular. In: Kendall FP, McCreary EK, Provance PG. Músculos Provas e Funções. 4. ed. São Paulo: Manole; 1995. p. 69-118.

9. Magee DJ. Avaliação Postural. In: Magee DJ. Disfunção Musculoesquelética. 3. ed. São Paulo: Manole; 2002. p. 105-57. 
10. Mikkersson M, Salminen JJ, Kautiainen H. Non-specific musculosketal pain in preadolescents. Prevalence and 1-year persistence. Pain. 1997;73:29-35. http://dx.doi. org/10.1016/S0304-3959(97)00073-0

11. Barbosa CMPL, Hangai L, Terreri MT, Len CA, Hilário MOE. Dor em membros em um serviço de reumatologia pediátrica. Rev Paul Pediatr. 2005;23(2):63-8.

12. Graup S, Dos Santos SG, Moro ARP. Estudo descritivo de alterações posturais sagitais da coluna lombar em escolares da Rede Federal de Ensino de Florianópolis. Rev Bras Ortop. 2010;45(5):453-9. http://dx.doi.org/10.1590/ S0102-36162010000500013

13. Steele E, Bialocerkowski A, Grimmer K. The postural effects of load carriage on young people - a systematic review. BMC Musculoskelet Disord. 2003;4:12.

14. Molina J, Silva SGL, Teles FM, Fraga MM, Paulo LTSP, BugniV, et al. Dor Musculoesquelética idiopática difusa na infância e na adolescência. Rev Paul Pediatr. 2011;29(2):294-9. http://dx.doi.org/10.1590/ S0103-05822011000200023

15. MasieroS, CarraroE, CeliaA, SartoD, Ermani M. Prevalence of nonspecific low back pain in schoolchildren aged between 13 and 15 years. Acta Paediatr. 2008;97(2):2126. http://dx.doi.org/10.1111/j.1651-2227.2007.00603.x

16. Iyer S. An Ergonomic Study of Chronic MusculosKeletal Pain in Schoolchildren. Indian J Pediatr. 2001;68(Oct):93741. http://dx.doi.org/10.1007/BF02722589

17. El-Metwally A, Salminen JJ, Auvinen A, MacFarlane G, Mikkelsson M. Risk factors for development of non-specific musculoskeletal pain in preteens and early adolescents: a prospective 1-year follow-up study. BMC Musculoskelet Disord. 2007;8:46. http://dx.doi. org/10.1186/1471-2474-8-46

18. Watson KD, Papageorgiou AC, Jones GT, Taylor S, Symmons DPM, Silmann AJ, et al. Low back pain in schoolchildren: the role de mechanical and psychosocial factors. Arch Dis Child. 2003;88(1):12-7. http://dx.doi. org/10.1136/adc.88.1.12

19. Taimela S, KujalaUl, Salminen JJ, Viljanen T. The prevalence of low back pain among children and adolescents. A nationwide cohort-based questionnaire survey in Finland. Spine. 1997;22(10):1132-6. http:// dx.doi.org/10.1097/00007632-199705150-00013

20. Rebolho MCT, Rocha LE, Teixeira LR, Casarotto RA. Prevalência de dor músculo esquelética e percepção de hábitos posturais entre estudantes do ensino fundamental. Rev Med (São Paulo). 2011;90(2):68-77.

21. Smith DR, Legatt PA. Back pain in the Young: A review of Studies conduct among school childrens and university students. Current Pediatrics Reviews: Benthan Science Publishers Ltda; 2007.

22. Garetth TJ, Gary JM. Predicting persistent low back pain in schoolchildren: A prospective cohort study. Arthritis Rheum. 2009; 61(10):1359-66. http://dx.doi.org/10.1002/ art.24696

23. Imamura ST, Kaziyama HHS, Imamura M. Lombalgia. Rev Med (São Paulo). 2001;80:375-90.

24. Greenspan J, Craft R, LeResche L, Arendt-Nielsen L, Berkley K, Fillingim R, et al. Studying sex and gender differences in pain and analgesia: A consensus report. Pain. 2007;132:S26-S45. http://dx.doi.org/10.1016/j. pain.2007.10.014

25. Fillingim R, King C, Ribeiro-Dasilva M, Rahim-Williams B, Riley J. Sex, gender, and pain: A review of recent clinical and experimental findings. Pain. 2009;10:447-485. http://dx.doi.org/10.1016/j.jpain.2008.12.001

26. Siambanes D, Maeines J, Butler E. Influence of School Backpacks on Adolescent Back Pain. J Pediatr Orthop. 2004;24(2):211-7. http://dx.doi. org/10.1097/01241398-200403000-00015

27. Chan G, Chen CT. Musculoskeletal effects of obesity. Curr Opin Pediatr. 2009;21(1):65-70. http://dx.doi.org/10.1097/ MOP.0b013e328320a914

28. Grimmer K, Williams M. Gender-age Environmental Associates of Adolescent Low Back Pain. Appl Ergon. 2000;31:343-360.

29. Negrini S, Carabalona R. Backpacks On! Schoolchildren's Perceptions of Load, Associations With Back Pain and Factors Determining the Load. Spine (Phila Pa 1976). 2002;27(2):187-95. http://dx.doi.org/10.1016/ S0003-6870(00)00002-8

30. Rodríguez-Oviedo P, Ruano-Ravina A, Pérez-Ríos M, García FB, Gómez-Fernández D, Fernández-Alonso A, et al. School children's backpacks, back pain and back pathologies. Arch Dis Child. 2012;97(8):730-2. http:// dx.doi.org/10.1136/archdischild-2011-301253

31. Rodrigues S, Montebelo MIL, Teodori RM. Distribuição da força plantar e oscilação do centro de pressão em relação ao peso e posicionamento do material escolar. Rev Bras Fisioter. 2008;12(1):43-8. http://dx.doi.org/10.1590/ S1413-35552008000100009

32. Santos SG, Almeida CR, Pizzol DRD, Pinguelli DO, Uem PD, Almeida EC, et al. Educação postural mediante um trabalho teórico. Rev Bras Ativ Fís Saúde. 1998;3(2):32-4.

33. Korovessis P, Koureas G, Zacharatos Z, Papazisis Z. Backpacks, Back Pain, Sagittal Spinal Curves and Trunk Alignment in Adolescents: a Logistic and Multinomial Logistic Analysis. Spine. 2005;30(2):247-55. http://dx.doi. org/10.1097/01.brs.0000150505.59690.1b

34. Contri DE, Petrucelli A, Perea DCBNM. Incidência de desvios posturais em escolares do $2^{\circ}$ ao $5^{\circ}$ ano do ensino fundamental. ConScientiae Saúde. 2009;8(2):219-24. http://dx.doi.org/10.5585/conssaude.v8i2.1637

35. Rego ARON, Scartoni FR. Alterações posturais de alunos de 5a e 6a séries do Ensino Fundamental. Fit Perf J. 2008;7(1):10-5.

36. Santos MM, Silva MPC, Sanada LS, Alves CRJ. Análise postural fotogramétrica de crianças saudáveis de 7 a 10 anos: confiabilidade interexaminadores. Rev Bras Fisioter. 2009;13(4):350-5. http://dx.doi.org/10.1590/ S1413-35552009005000047

37. Mackenzie WG, Sampath JS, Kruse RW, SheirNeiss GJ. Backpacks in children. Clin Orthop Relat Res. 2003;409:78-84. http://dx.doi.org/10.1097/01. blo.0000058884.03274.d9

38. Sato T, Ito T, Hirano T, Morita O, Kikuchi R, Endo $\mathrm{N}$, et al. Low back pain in childhood and adolescence: a cross-sectional study in Niigata City. Eur Spine 
J. 2008;17:1441-7. http://dx.doi.org/10.1007/ s00586-008-0788-5

39. Andersen LB, Wedderkopp N, Leboeuf-Yde C. Association between back pain and physical fitness in adolescents. Spine. 2006;31:1740-4. http://dx.doi. org/10.1097/01.brs.0000224186.68017.e0

\section{Correspondence}

Isabel Aparecida Porcatti de Walsh

Universidade Federal do Triângulo Mineiro

Instituto de Ciências da Saúde

Departamento de Fisioterapia Aplicada

Rua Capitão Domingos, 309

CEP 38025010, Uberaba, MG, Brazil

e-mail: ewalsh@terra.com.br 